\title{
Congenital glucose galactose malabsorption
}

Pujith Wickramasinghe', Sanath P Lamabadusuriya ${ }^{2}$ and H A S Lalani ${ }^{3}$

(Index words: Clinical features, diagnosis, dietary management)

\section{Introduction}

Congenital glucose galactose malabsorption (CGGM) is a rare autosomal recessive disorder, which presents as a protracted diarrhoea in early neonatal life. It is due to a defect in sodium coupled transport of glucose and galactose in the enterocyte (1). Diarrhoea in CGGM is osmotic, caused by accumulation of unabsorbed glucose and galactose in the intestine (2), which results in severe malnutrition (3). When glucose and galactose are eliminated from the diet, infants with CGGM thrive and dietary intervention after early diagnosis will result in normal growth and development.

\section{Case report}

The first product of a consanguineous marriage weighing $2.82 \mathrm{~kg}$ at birth developed a profuse watery diarrhoea on the fifth post-natal day, while exclusively breast fed. He was admitted on the $11^{\text {th }}$ day and treated for hypernatraemic dehydration with intravenous fluids, and a lactose free formula was started. On day 15 he weighed $2.4 \mathrm{~kg}$ and was severely dehydrated and emaciated. Investigations revealed a random blood glucose $3.5 \mathrm{mmol} /$, serum $\mathrm{Na}^{+} 151.0 \mathrm{mmol} / \mathrm{l}$, serum $\mathrm{K}^{+} 3.2 \mathrm{mmol} / \mathrm{l}$ haemoglobin $14.6 \mathrm{~g} / \mathrm{dl}$, haematocrit $44 \%$, stool smear- no pus or red blood cells; reducing substances + ; stool culture negative for Salmonella, Shigella and Escherichia coli. Substitution of a lactose free formula for breast milk did not have any impact and reducing substances persisted in the stool. Congenital chloride diarrhoea was excluded (stool electrolytes $\mathrm{Na}^{+} 19.0 \mathrm{mmol} /, \mathrm{K}^{+} 10.86 \mathrm{mmol} / /$ and $\mathrm{Cl}^{-} 27.0 \mathrm{mmol} / /$ ). Normal serum zinc levels excluded acrodermatitis enteropathica. At 3 weeks, when exclusively maintained on intravenous fluids the diarrhoea settled. Introduction of $5 \%$ dextrose orally resulted in recurrence of watery stools loaded with reducing substances. Then it was evident that the child was having a malabsorption syndrome rather than a secretory diarrhoea. Thereafter he was managed with intravenous 5\% dextrose and fresh frozen plasma. On the 34th day, parenteral nutrition with Aminoplasmin and Lipofundin (Braun) was started. These were also given orally, and well tolerated. Thereafter, the stools became semi-solid with disappearance of reducing substances, which favoured a specific carbohydrate absorption defect. A tentative diagnosis of CGGM was made and Galactomin 19 (Cow \& Gate Nutricia), which is a glucose galactose free formula, was introduced. It was well tolerated and at 13 weeks the weight had increased to $4.8 \mathrm{~kg}$. Boiled and blended chicken, Casilan 90 (Glaxo), pear and apple juice (which are low in glucose and galactose) were then introduced. MCT oil (Mead Johnson) was also given and well tolerated. At 18 weeks, soup containing mashed potato, dhal, beans, dried sprats, carrots and green leaves

'Lecturer and ${ }^{2}$ Senior Professor, Department of Paediatrics, Faculty of Medicine, University of Colombo; and ${ }^{3}$ Paediatric Registrar, Lady Ridgeway Hospital, Colombo. (Revised version accepted 20 December 2000). 
was given with rice-cunjee. He weighed $5.6 \mathrm{~kg}$ and passed two well formed stools daily. At nine months he weighed $7.8 \mathrm{~kg}$ ( $16.8 \%$ below reference range) and the development was appropriate for the age.

\section{Discussion}

Although a definitive diagnosis of CGGM is made by demonstrating a cotransporter defect after small intestinal biopsy, dietary manipulation may suffice in establishing it (4). In this patient, although the diagnosis could not be confirmed due to lack of facilities, the diagnosis of CGGM seems certain based on the clinical presentation and the response to dietary manipulations.

Once a presumptive diagnosis is made proper dietetic management should be initiated with a diet free of glucose and galactose, with fructose as the sole source of carbohydrate. Soya based products are not useful as they have glucose or glucose polymers as carbohydrate. All medications should be free of carbohydrate. By about the $4^{\text {th }}$ month, complementary foods could be introduced (1). Home made formulae based on minced chicken, egg and Casilan can be made into a mixture and adjusted to suit individual requirements (5). The infant should be monitored closely for gastrointestinal tolerance of the food, based on stool frequency and consistency. Parents should be encouraged to introduce a variety of foods gradually one at a time. After the first year carbohydrate containing foods could be introduced gradually in small quantities and the tolerance monitored. Periodically the weight gain and linear growth should be monitored. Supplementation with vitamins and minerals is also required. Alternative sweeteners such as honey may be used after 12 months. With increasing age children begin to tolerate moderate amounts of glucose and galactose in the diet as the colonic flora adapt to chronic loading of glucose by increasing fermentation of the unabsorbed carbohydrate to short chain fatty acids (1).

\section{References}

1. Abad-Sinden A, Borowitz S, Meyers R, Sutphen J. Nutrition Management of congenital glucose-galactose malabsorption: A case study. Journal of the American Dietetic Association 1997; 97: 1417-21.

2. Gracey M, Burke V. Sugar induced diarthoea in children. Archives of Disease in Childhood 1973; 48: 331-6.

3. Abdulla AMA, EI.Mouzan MI, Shiekh OKE, Mazyad AA. Congenital glucose-galactose malabsorption in Arab children. Journal of Paediatric Gastroenterology and Nutrition 1996; 23: 561-4.

4. Martin MG. The biology of inherited disorders of the gastrointestinal tract Part 1: Gastrointestinal disorders. Journal of Paediatric Gastroenterology and Nutrition 1998; 26: 321-35.

5. Francis DEM. Diets for sick children. $4^{\text {th }}$ Edition. Oxford: Blackwell scientific publications, 1987: 264-70.

\section{Meetings}

1. Joint Conference of Indian Association for Study of Liver and European Association for the Study of the Liver, Goa 23 - 25 March 2001

Information: Dr Deepak N. Amarapurkar, Bombay Hospital and Medical Research Centre, New Wing, MRC Building, Room No. 107, 12 Marine Lines, Mumbai 400020, Maharashtra, India.

2. ICMR Course on Genetic Counselling, Lucknow, Uttar Pradesh 17-28 April 2001

Information: Dr S. R. Phadke, Assistant Professor, Department of Medical Genetics, Sanjay Gandhi Postgraduate Institute of Medical Sciences, Lucknow 226014, Uttar Pradesh, India.

3. Second International Course on Critical Care Nephrology, Vicenza, Italy 22 - 25 May 2001

Information: Prof Claudio Ronco, Department of Nephrology, St Bortolo Hospital, via Rodolfi, 36100 Vicenza, Italy.

4. International Congress of Toxicology - ICT-IX, Brisbane, Qld, Australia 8 - 13 July 2001 Information: Congress Secretariat Intermedia, PO Box 1280, Milton, Qld, Australia.

5. Fourth International Congress on Peer Review in Biomedical Publication, Barcelona, Spain 14 - 16 September 2001 Information: Annette Flanagin, Jama, 515 N State St., Chicago IL 60619, USA.

6. National Conference of the Indian Association of Surgical Gastroenterology, Cuttack, Orissa September 2001 Information: Dr Mihir K. Mohapatra, Department of G. I. Surgery, S.C.B. Medical Colllege, Cuttack, Orissa, India.

7. Seventh Congress of the Asian Society of Transplantation, New Delhi, India 21 - 25 November 2001 Information: Nandini Prasad, nandini_del@tci.co.in

8. Third World Congress on Paediatric Esopphageal Caustic Burn, New Delhi, India 1 - 3 February 2002 Information: Secretariat, Department of Paediatric Surgery, All India Institute of Medical Sciences, New Delhi 110029, India.

9. Regional Scientific Meeting of the International Epidemiological Association, Khajuraho, Madhya Pradesh 25- 27 February 2002

Information: Dr Babu L. Verma, Division of Biostatistics, Department of Preventive and Social Medicine, M.L.B. Medical College, Jhansi 284128, Uttar Pradesh, India.

10. Fourteeth International Conference on AIDS, Barcelona, Spain, July 2002 Information: Conference Program Secretariat, Edifici Apollo X, Balmes, 200 at 9, 08006 Barcelona, Spain. 